\title{
Fatigue damage analysis of GFRP composites using digital image correlation
}

\author{
Hassan Gonabadi ${ }^{1}$ (D) Adrian Oila ${ }^{1}$ (D) $\cdot$ Arti Yadav $^{1} \cdot$ Steve Bull $^{1}$ (D
}

Received: 11 August 2020 / Accepted: 31 December 2020 / Published online: 18 February 2021

(c) The Author(s) 2021

\begin{abstract}
Glass fibre reinforced polymer composites are frequently used in marine applications where the combined effects of cyclic loads and the seawater environment limit their fatigue life. This paper aims to demonstrate the degradation that seawater causes to the stiffness of the composites. Three-point bending fatigue properties of cross-ply woven glass fibre composites commonly used to manufacture tidal turbine blades are reported for both wet and dry conditions. Failure analysis based on the Digital Image Correlation method was performed to identify damaged zones on the test coupon surface and to follow failure progression during the fatigue tests. To characterize the damage in the composite, stiffness degradation has been monitored during the entire fatigue history. Scanning electron microscopy was used to identify multiple failure mechanisms on the specimen fracture surface. In addition, for further verification of microscopy results, X-Ray Micro-computed tomography, was used to characterize the internal damage such as delamination. From the full-field strain measurement technique and microscopic examination of failed samples, it was found that distributed localized strains are evidence of the number of resin cracks and de-bonded areas. SEM examination shows a degraded fibre/matrix interface region due to the action of seawater.
\end{abstract}

Keywords Composites · Tidal turbine blades · Digital image correlation · Fatigue

\begin{tabular}{ll}
\multicolumn{2}{l}{ List of symbols } \\
$F$ & Force \\
$L$ & Distance between supports in 3 PB test set up \\
$b$ & Width of test specimen \\
$h$ & Thickness of test specimen \\
$d$ & Vertical deflection \\
$\sigma_{f}$ & Flexural stress \\
$\mathbf{e}_{f}$ & Flexural strain \\
$\mathrm{e}_{\max }, i$ & Max initial strain \\
$\mathrm{e}_{x x}$ & Longitudinal normal strain \\
$\mathrm{e}_{y y}$ & Transvers normal strain \\
$\mathrm{e}_{x y}$ & Shear strain \\
$K$ and $A$ & Constants in power law equation
\end{tabular}

Hassan Gonabadi

hassan.izadi-gonabadi@newcastle.ac.uk

Adrian Oila

adrian.oila@newcastle.ac.uk

Arti Yadav

arti.yadav@newcastle.ac.uk

Steve Bull

steve.bull@newcastle.ac.uk

1 School of Engineering, Newcastle University, Newcastle upon Tyne, UK

$\begin{array}{ll}N_{f} & \text { Number of cycles to failure } \\ D & \text { Damage } \\ E & \text { Elastic modulus } \\ E_{i} & \text { Initial Elastic modulus } \\ \mathrm{E}_{\mathrm{f}} & \text { Final elastic modulus } \\ X_{10}^{\text {lin }} & \text { Point of line corresponding to } 10 \% \text { of consumed } \\ & \text { fatigue life } \\ X_{90}^{\text {lin }} & \text { Point of line corresponding to } 90 \% \text { of consumed } \\ & \text { fatigue life } \\ \Delta X_{\%} & \text { Index of irreversible composite degradation }\end{array}$

\section{Introduction}

One of the major challenges in the marine energy industry is the ability to predict fatigue failure of composite structures. High-cycle fatigue occurs in many marine energy conversion devices; in particular tidal turbine blades that are subject to an environmentally affected fatigue load, and therefore the corrosion fatigue capability is a life-limiting factor. Glass fibre reinforced epoxy resin composites are frequently used in the design of tidal turbine blades and the primary fatigue failure modes are delamination and fibre breakage (Boisseau et al. 2013). In this application, although there is a 
layer of gel-coat to protect the GFRP material; under some circumstances due to high static and cyclic loads the gel-coat could fail, leaving the GFRP material directly exposed to the seawater environment. Therefore, it is important to understand the amount of degradation caused by seawater and its effect on the mechanical properties and failure mechanisms of these materials.

Determining the resistance of composites to the complex state of fluctuating stress is a fundamental problem in many engineering applications. Composite materials exhibit very complex failure phenomena including multiple damage mechanisms and their interactions. This is due to the anisotropic characteristics of the mechanical properties of laminates as well as the presence of interfaces causing stress redistribution. Unlike isotropic materials where the predominant failure mechanism is the initiation and propagation of a single crack, fatigue failure in fibre reinforced composites is due to general degradation throughout the specimen volume. Fatigue failure modes in composites are resin cracking, interfacial de-bonding between fibre and polymer matrix, delamination and fibre breakage (Vassilopoulos and Keller 2011). The different damage mechanisms coupled with complex strain fields significantly limit understanding of the true nature of fatigue failure.

The most important obstacle to predict the fatigue life of composites is the lack of information regarding composite material properties that could be used as a basis for the development of the fatigue failure criteria (Schaff and Davidson 1997, Quaresimin et al. 2010). In order to establish acceptable failure criteria, fatigue failure can be defined as stiffness degradation which is a suitable failure criterion for many composites. Changes in stiffness as an index of composite microscopic damage can be easily measured and interpreted. In fatigue bending, the degradation rate is related to the stress within the composite material. Initially, a high load is required to deflect the test coupon. As the cyclic loading continues the load required for the same deflection becomes smaller. This reduction in load (and stress) within the specimen signals the degradation. Therefore, in the process of damage evolution of a constant bending amplitude fatigue test, at the beginning of life (first stage), damage initiation and propagation causes a drop in the composite stiffness; in the second stage, a gradual material degradation which is a function of cyclic load levels and environmental conditions is observed. Finally, the third stage follows with a catastrophic reduction of material properties and a large loss in stiffness in the damaged zones (Shokrieh and Lessard 1997, Giancane et al. 2010).

In terms of the environmentally affected fatigue performance of composite materials it must be noted that environmental exposure and mechanical forces can act together to speed up the degradation process in the composite material i.e. mechanical forces accelerate fluid penetration and fluid diffusion accelerates damage induced by mechanical stresses (Suri and Perreux 1995). In the literature, It has been shown that the mechanisms of environmental stress corrosion cracking (ESCC) in FRP composites (Renaud and Greenwood 2005) are fibre and fibre/matrix interface degradation which is due to the water penetration into the network of resin cracks and de-bonded fibres (Schmitz and Metcalfe 1966, Metcalfe and Schmitz 1972, Vauthier et al. 1995, Izadi Gonabadi 2019). The main causes of degradation are either corrosive species (i.e. chloride) or the mechanisms of ionic exchange between metallic cations $\left(\mathrm{Na}^{+}\right.$and $\left.\mathrm{K}^{+}\right)$ and hydrogen ions $\left(\mathrm{H}^{+}\right)$from the attacking environment. In the latter mechanisms, separation of metallic ions from the fibre surface can develop nucleation sites for micro-cracks (Charles 1958b, a; Charles 1958b, a; Izadi Gonabadi 2019).

The other factor causing the degradation of polymerbased composite tidal turbine blades is tribological phenomena such as sediment and solid particle erosion as well as cavitation erosion. Tribological mechanisms in GFRP composites have been investigated by considering the effects of erosion parameters, contributing to understand the effect of seawater environment on the degradation of composite (Ahamed et al. 2016, Rasool et al. 2016, Rasool and Stack 2019).

Digital image correlation (DIC) is non-contact optical technique for the measurement of mechanical displacement and strain. Numerous investigations of damage development using DIC have been reported in the literature (Chu et al. 1985, Sun et al. 1997, Zhang et al. 2006, Godara and Raabe 2007, Canal et al. 2012, He et al. 2012, Laurin et al. 2012, Crupi et al. 2013). Inter-laminar shear and tensile properties of composites have been investigated using the DIC method where full-field strain maps show inhomogeneous strain distribution in the areas on the sample surface where delamination occurs (Chu et al. 1985, Godara and Raabe 2007, Canal et al. 2012, He et al. 2012, Laurin et al. 2012, Crupi et al. 2013), however, little knowledge is available about applying DIC analysis to environmentally assisted fatigue loads.

In the past, the investigations of the fatigue behaviour of GFRP composites have been focused on tensile fatigue, with less attention being given to the fatigue behaviour under bending modes especially in the case where the material is undergoing fluctuating loads in a fluid. The present investigation provides data for fatigue tests of specimens during seawater exposure. A large number of coupons were tested under a three-point bending ( $3 \mathrm{~PB}$ ) fatigue load configuration at various constant displacements in both seawater and air. Using the DIC technique a better knowledge of fatigue behaviour of a standard epoxy/glass fibre composite was acquired by measuring surface strain maps during the fatigue test. The DIC was also used to determine the change in elastic modulus (modulus decay) which is associated with fatigue damage. Modulus decay gives clear evidence about 
Fig. 1 Micrographs of the GFRP laminate, a SEM reveals the cross section of microstructure with biaxial fibre orientation. b 3D reconstructed volumetric model obtained by $\mu-\mathrm{CT}$
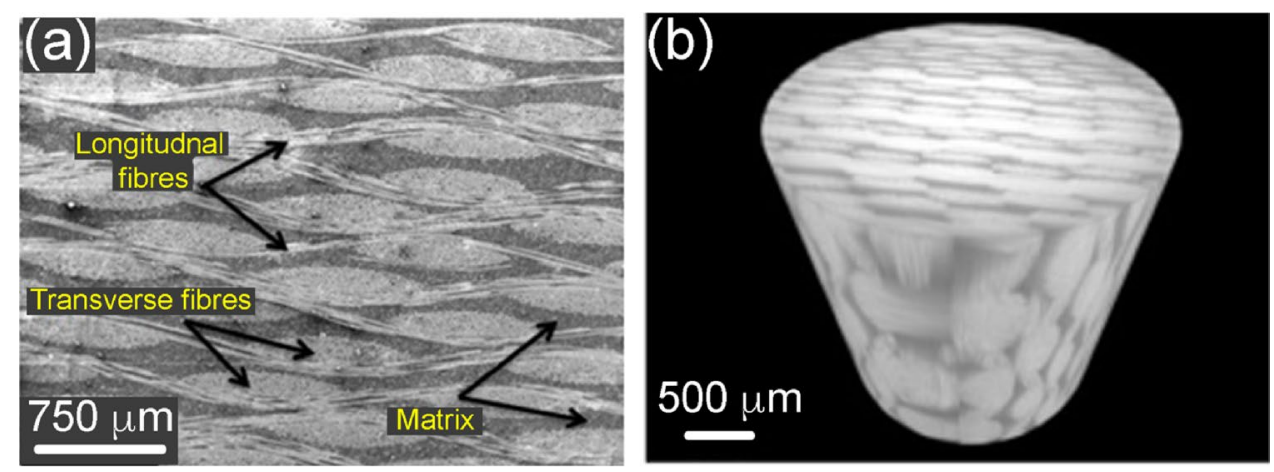

Table 1 GFRP composite specifications

\begin{tabular}{lc}
\hline Weave style & $\begin{array}{c}\text { Symmetric laminate with plain } \\
\text { woven fabric as shown in }\end{array}$ \\
& Fig. 2 \\
Layups & $\left(0^{\circ} / 90^{\circ}\right)$ \\
Thickness of each lamina & $0.2 \mathrm{~mm}$ \\
\hline
\end{tabular}

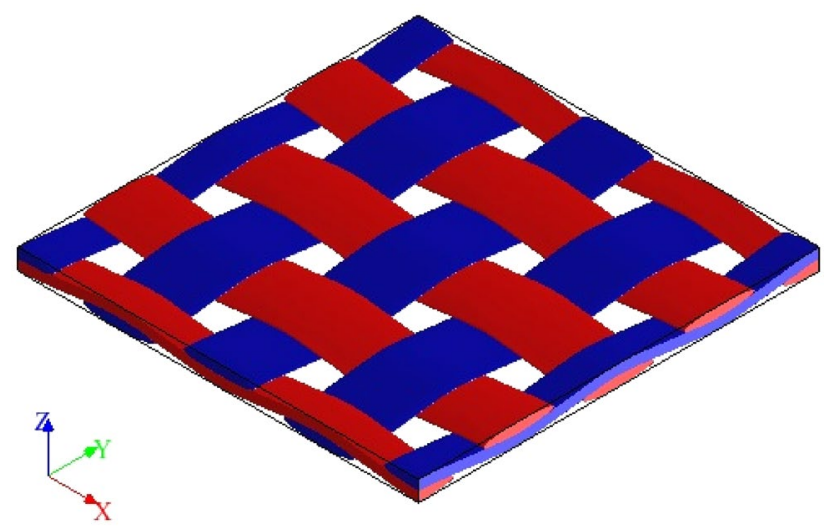

Fig. 2 Schematic of plain-woven fabric, (ply thickness: $0.2 \mathrm{~mm}$ )

damage localization and gradual degradation of the mechanical properties of composites during their fatigue history.

\section{Experimental}

\subsection{Material}

The material under study is woven E-glass fibre reinforced epoxy resin composite produced by a commercial supplier to the G10 standard (Johnson and Johnson 1987). The asreceived materials were $1.2 \mathrm{~m} \times 1.2 \mathrm{~m} \times 0.005 \mathrm{~m}$ plates. Plates were manufactured using a vacuum-assisted resin infusion process. Structurally, the reinforcement material consists of longitudinal and transverse bundles of glass fibres as shown in Fig. 1. The fibres are in a plain-woven

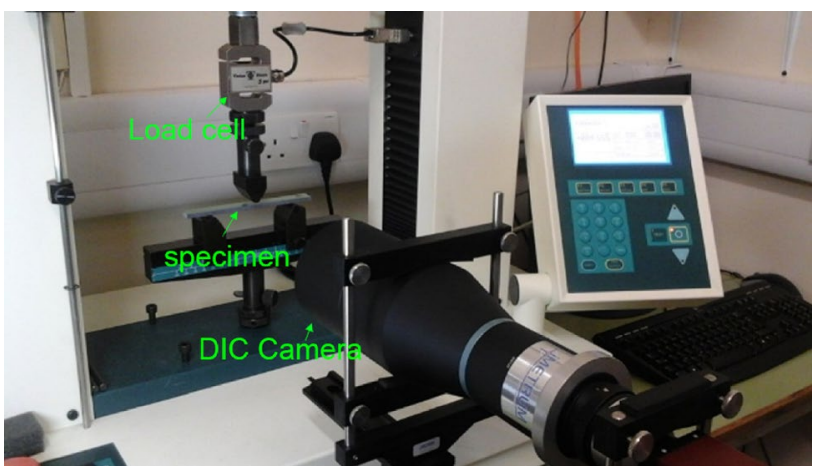

Fig. 3 Experimental set up for a 3 PB test equipped with DIC system

fabric (orthogonally oriented). 25 plies of fabric were laminated in a stacking sequence of $\left(0^{\circ} / 90^{\circ}\right)$ layup. By the matrix burn-off method the glass fibre volume fraction of the GFRP composites was determined as approximately $35 \pm 2 \%$. To examine the quality of GFRP laminates, scanning electron microscopy was used to observe a polished cross section (Fig. 1). The glass transition temperature, $T_{\mathrm{g}}$, of the epoxy resin matrix was measured by Differential Scanning Calorimetry (DSC) to be $122{ }^{\circ} \mathrm{C}$. Table 1 lists the composite laminate specification.

\subsection{Quasi-static three point bending test (3PBT)}

The quasi-static tests have been conducted by means of a universal test machine with a $50 \mathrm{KN}$ load cell in the threepoint bending ( $3 \mathrm{~PB}$ ) mode. This test produces a tensile stress in the convex side and compressive stress on the concave side. This creates a region of shear stress along the midline; in order to ensure that this is minimized the sample thickness must be kept to less than one-sixteenth of the distance between the lower supports (span). The machine was also equipped with a video gauge (DIC measurement set up) to record the strain during the test (Fig. 3). Bar specimens of dimensions as shown in Table 2 were cut from plates according to the standard test method of BS EN ISO 14,125 (STANDARD and ISO 1998). During the test, a 
Table 2 Geometrical dimensions of specimens

\begin{tabular}{llll}
\hline Values & Length $(\mathrm{mm})$ & Width $(\mathrm{mm})$ & Thickness $(\mathrm{mm})$ \\
\hline Nominal & 150 & 15 & 5 \\
Actual & $150 \pm 0.8$ & $15 \pm 0.3$ & $5 \pm 0.05$ \\
\hline
\end{tabular}

load cell and the video gauge record the load and displacement, respectively. Force-displacement was converted to stress-strain to standardize the curves for all samples, this was done by applying standard bending equations (developed for a homogeneous material by assuming a constant sample curvature), where $F$ is the force applied by the loading roller, $L$ is the distance between supports, $h$ and $b$ are thickness and width of the test coupon, respectively, and $D$ is the vertical deflection of the sample at the centre.

$\sigma_{\mathrm{f}}=3 F L / 2 b h^{2}$

$e_{\mathrm{f}}=6 D h / L^{2}$

\subsection{PB fatigue test}

Fatigue tests were performed in the $3 \mathrm{~PB}$ mode at the loading frequency of $1 \mathrm{~Hz}$ in two different environments, i.e. natural North Seawater from the Dove Marine Laboratory (3.5\% dissolved salts, predominantly $\mathrm{NaCl}(2.4 \%), \mathrm{MgSO}_{4}(0.5 \%)$ and $\mathrm{MgCl}_{2}(0.3 \%)$ and laboratory air. The specimens were cut from the same panel to minimise sample-to-sample variation. A total of 60 samples were obtained; 30 samples were tested under fatigue loading while exposed to air, whilst the other 30 specimens were tested under fatigue loading while immersed in seawater with the same configuration at room temperature. 3 PB fatigue tests involved cycling specimens under constant deflection using a specially designed test machine (load cell of $25 \mathrm{KN}$ ) until failure. In order to avoid specimen motion, impact on the sample and the variation of the loaded point on test coupon during the fatigue test, the strain ratio was kept at $R=\frac{\varepsilon_{\min }}{\varepsilon_{\max }}=0.1$. The configuration for the 3 PB fatigue test (Fig. 4) was the same as used for quasistatic 3 PB test in terms of test coupon dimensions, geometry, span supports and loading roller positions. According to the standard test method of ES BN ISO13003 (ISO 2003) for bending fatigue behaviour of composites, five coupons were tested at each of different strain levels between 50 and $90 \%$ of their dry maximum static strain.

Fatigue tests were interrupted at regular time intervals to perform quasi-static $3 \mathrm{~PB}$ tests to measure elastic modulus decay due to the cyclic loads. Post static bending tests on fatigue loaded samples also included a DIC measurement to obtain a full-field strain map on the sample surface.

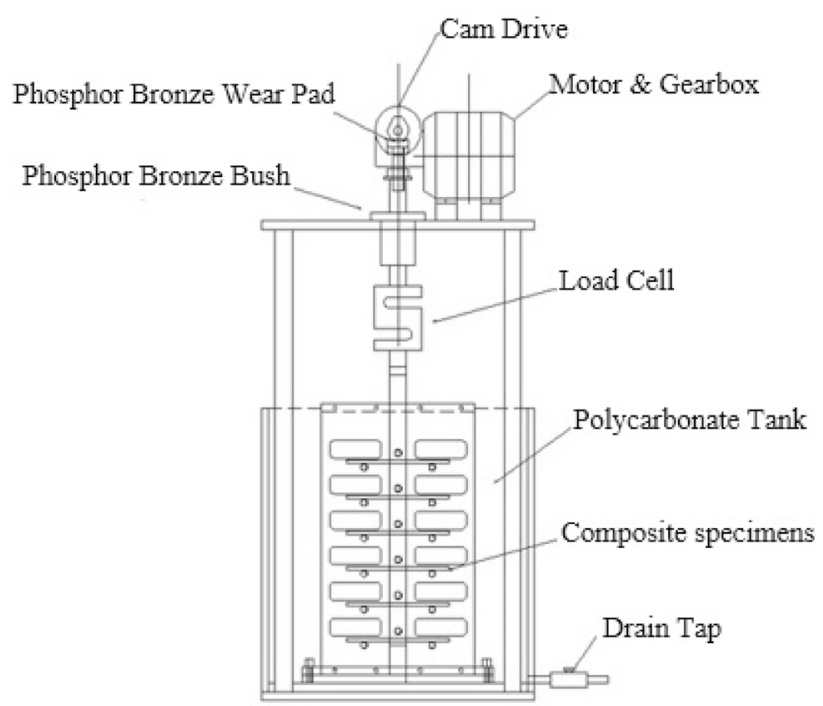

Fig. 4 Exploded-view schematic of 3 PB fatigue rig

Surface related damage during fatigue was observed and failure mechanisms were analysed using reflected light and Scanning Electron Microscopy (SEM). The fracture surfaces were sputter coated with gold prior to SEM examination.

\subsection{Digital image correlation}

DIC is a full-field strain measurement technique which can be used to build the strain maps in composite materials, providing information about strain localization (Izadi Gonabadi 2019). The technique is based on comparing digital images before and after deformation and tracking blocks of pixels in a target area. This process is viable when the object surface has a random speckle pattern, which depending on the surface morphologies of the samples, may need to be created first. In this study, the pattern was created by alternate spraying white and black paint on the sample surface. The DIC technique can also be used to monitor the evolution of strain during the mechanical testing of materials (Metwalli et al. 1987; Ukyo and Masuda 2004), to investigate the crack tip and crack propagation (Abanto-Bueno and Lambros 2002, Lee et al. 2009, Richter-Trummer et al. 2011), and to detect damage development in composites (Izadi Gonabadi 2019). However, as the spatial resolution in DIC method depends on the optical resolution of the experimental set up and the quality of speckle pattern, studies on the above phenomena, in particular crack propagation, are challenging. Although in many cases large crack opening can be identified using the naked eye, smaller cracks that are not visible to the naked eye can be identified using combined digital image correlation and dye penetrant on the surface of the sample. By using DIC as a map of localized deformation/strain, with one image taken before cracking occurs and one taken 
afterwards, the full extent of crack opening and crack propagation paths can be examined (McCormick and Lord 2010).

The CCD camera (IMETRUM) with a $300 \mathrm{~mm}$ working distance lens was placed in front of the specimen so that it could be viewed edge on during bending. The camera features a spatial resolution of $0.0055 \mathrm{~mm} / \mathrm{pixel}$ and was equipped with lenses of 0.193 magnification. Digital images of the specimen surface were recorded with a frequency of $25 \mathrm{~Hz}$. After testing, the series of digital images were processed using the VIC 2D software (from Correlated Solutions, Inc). A field size $(5 \mathrm{~mm} \times 60 \mathrm{~mm})$ was defined on each initial image of the fatigued samples (Fig. 5). The most important parameters related to calculations using DIC software are facet size, step size and interpolation type. The results here were obtained with facet size of 30 pixels corresponding to $165 \mathrm{~m}$, step size to 10 pixels which is equal to a spatial resolution of $55 \mathrm{~m}$ and bi-cubic interpolation.

\subsection{X-ray 3D micro-computed tomography}

X-ray $(\mu-\mathrm{CT})$ measurements were carried out using an $\mathrm{X}$ Radia/Zeiss Versa XRM 410. The system consists of a micro-focus X-ray source operating at $150 \mathrm{kV}$, within a

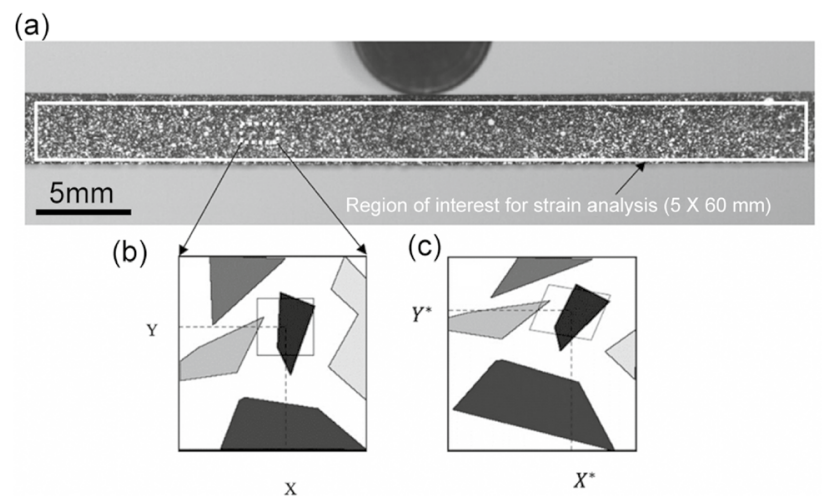

Fig. 5 a An image of spray-coated specimen showing the stochastic speckle pattern and the region of interest for the strain analysis. Schematic drawing illustrating the fundamentals of the DIC approach indicating b initial image (before deformation), $\mathbf{c}$ distorted image (after loading) maximum power of $10 \mathrm{~W}$. The highest achievable resolution is $0.9 \mu \mathrm{m}$. A spot size of $<5 \mu \mathrm{m}$ is obtained at $4 \mathrm{~W}$. A precision object manipulator with two translations and one rotation facilitates rotating the sample for the acquisition of tomographic data, raising/lowering the sample to select a region of interest, and translation along the optical axis to adjust the magnification. The X-ray detector consists of an X-ray scintillator screen which is fiber optically coupled (at an image ratio of 3.7:1) to a high resolution (1024/1024 pixel) cooled $2 \mathrm{k} \times 2 \mathrm{k}$ 16bit CCD $\mathrm{x}$-ray camera.

\section{Results and discussion}

In this study, using a data logger connected to the load cell in the fatigue rig, the load-time response during fatigue tests is recorded (Fig. 6a). When the first load drop occurs (indicating failure in one of the samples), the fatigue test was interrupted and the samples were checked under a light microscope to identify the failed sample which was removed. The fatigue test is then carried on until the next load drop occurs. The same procedure was used for the rest of the samples until the all have failed. Although fatigue tests have been conducted for multiple samples with the above procedure, a fatigue test was repeated using a single sample for each strain level to check consistency; each test is therefore repeated 5 times (Fig. 6b). As the bending fatigue tests are conducted under strain control mode, the applied load, required to keep the given deflection constant, decreases with the number of cycles. In other words, stiffness degradation of composites during fatigue tests can be confirmed directly via the output from the fatigue test rig.

\subsection{Strain-life curves}

Various curves can be drawn for the presentation of fatigue test results and life prediction. In this study a power-law relationship between maximum initial strain $\left(\varepsilon_{\max , i}\right)$ and fatigue life was used.
Fig. 6 Load versus time during the fatigue test of a multiple specimens b single specimen captured via data logger (applied strain level is $1.2 \%$ )
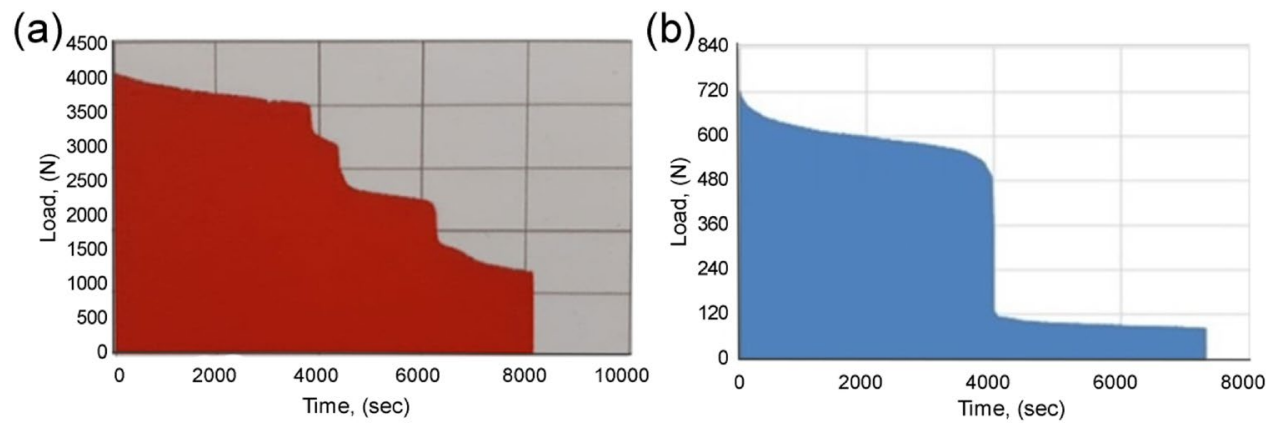
$e_{\max , \mathrm{i}}=K\left(\log N_{\mathrm{f}}\right)^{-A}$

where $N_{\mathrm{f}}$ is the number of cycles to failure, $K$ and $A$ are constants. The constants can be determined by plotting the strain versus number of cycles to failure and fitting Eq. 2 to the data. In order to determine the lifetime diagram, five specimens were tested at a minimum of seven separate levels of imposed strain. Also for measuring the monotonic strength and its corresponding deflection/strain level for the selected test method, five specimens were initially tested under $3 \mathrm{~PB}$ to failure. The fatigue failure criterion was defined as the onset of a DIC-detectable delamination. The strain-life fatigue test results for GFRP composite along with the corresponding fits to Eq. 2 are shown in Fig. 7, in which each data point indicates one valid flexural fatigue test. Comparing $\varepsilon-N$ curves obtained in the air with seawater environment provides an indication of the durability of these materials and clearly reveals the influence of the environment on reducing fatigue life.

As can be seen in Fig. 7, fatigue data points can be classified into two distinctive regimes, a regime of stress-environment dependence, and a regime of stress-dependence and environment-independence. This is shown by a transition line and the two arrows in Fig. 7. For samples fatigue loaded at high strain levels (strain level higher than $1.1 \%$ ), fatigue data points are mostly overlapping, so low cycle fatigue of composite can be categorized as in a stress-dependent and environment-independent regime. A substantial difference in fatigue data points can be observed for those of specimens tested at higher cycles (strain levels lower than 1\%). Specimens tested in air survived to longer lives approximately 5 $\times 10^{6}$ cycles, however, specimens tested in seawater failed at less than $\sim 10^{6}$ cycles, consequently high cycle fatigue can be classified as a stress-dependent and environment-dependent regime.

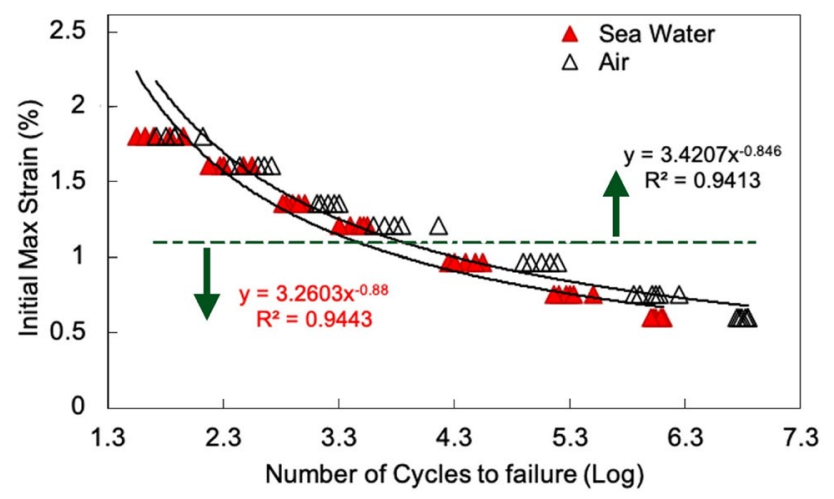

Fig. 7 Strain -Number of cycles to failure plots of GFRP composites under different strain level in wet and dry conditions. The standard uncertainty in the maximum applied strain is estimated as $0.1 \%$
The power-law coefficients determined by fitting the experimental data using the least-squares method are shown in Fig. 7. For the prediction of the fatigue life of the composites under strain levels outside the testing range, Eq. 2 is used. The regression fitting parameter $(A)$ is 0.846 for GFRP in air and 0.88 in seawater indicating the strength loss per decade of cycles of the material. The loss in strength per decade is higher for GFRP composites when tests are performed in seawater.

\subsection{Fatigue failure analysis using DIC}

Damage analysis based on DIC has been conducted to locate the damaged zones on the specimen surface and to follow failure evolution during fatigue life. Figure 8 shows an example of the random speckle pattern created using black and white spray paints on a sample. The figure also shows a typical failure in one of the fatigue bending specimens after 5.9 million cycles. The failure mode is a delamination starting beneath the loading roller (upper support) on the tension side of the sample. All bending specimens exhibited the same behaviour.

Figure 9 shows the results of strain analysis at the very beginning of cycling and at the peak cyclic strain equal to $30 \%$ of the ultimate static strain. The displacements measured in this method were numerically differentiated using the strain computation algorithm built in the VIC-2D software to compute the Lagrange surface strain tensor components. With reference to the Fig. 9, distribution of axial strain through the thickness direction at various length coordinates are shown in Fig. 10. Applying deflection of $2 \mathrm{~mm}$ (equivalent to $30 \%$ of maximum deflection in static $3 \mathrm{~PB}$ test) at the centre of 3 PB test specimen, the flexural strain using Eq. 1 is calculated to be $0.6 \%$ indicating that DIC calculated strains agree well with the strain values calculated from Eq. 1.

Figures 11 and 12 illustrate typical DIC analysis results for the surface strain components, loaded in the $x-z$ principal material plane, at the peak cyclic strain equal to $30 \%$ of ultimate static strain in both seawater and air environments, respectively. Figures 13 and 14 show the typical flexural normal engineering strain histories from the starting point at the different peak flexural strain, as functions of cycles

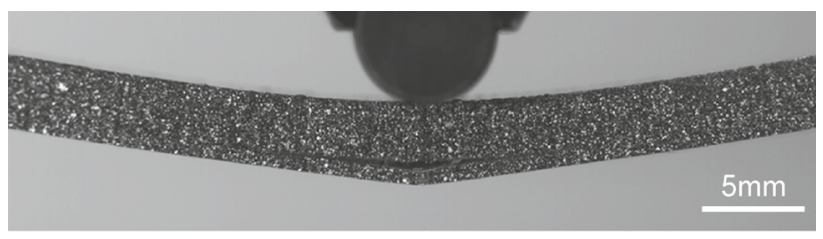

Fig. 8 E-glass/epoxy three-point bend fatigue test specimen failure at 5,9 million cycles 


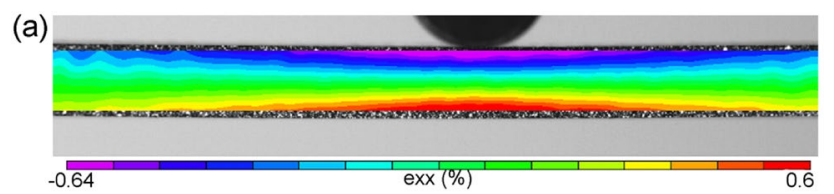

(b)

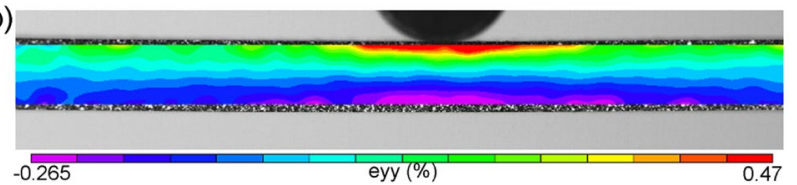

(c)

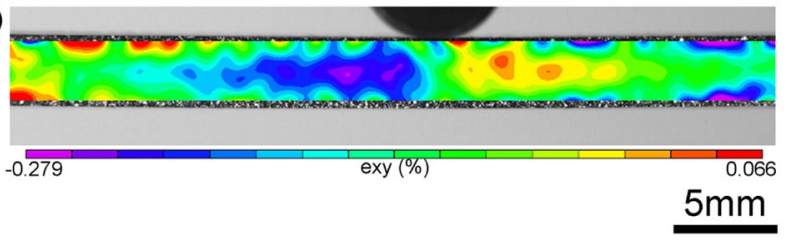

Fig. 9 Lagrange strain tensor components for a $3 \mathrm{~PB}$ fatigue test at peak strain equal to $30 \%$ of ultimate static strain at the beginning of life cycle (a), longitudinal normal strain, $\boldsymbol{e}_{x x}(\mathbf{b})$, transverse normal strain, $\boldsymbol{e}_{y y}$ and (c), shear strain, $\boldsymbol{e}_{x y}$ during fatigue tests. The last point in the fatigue history matches to the onset of a DIC-detectable delamination. A 64-116\% increase in the localized flexural normal strain can be observed during the first $90 \%$ of fatigue life in both seawater and air conditions, and a rapid and large increase of the flexural normal strain occurs shortly before the onset of delamination. A possible reason for this response is the increase in the non-visible damage accumulation in the epoxy resin prior to detectable cracking.

By comparing Figs. 11 and 12 and according to the microscopic features of GFRP composites it can be found that the damaged surface of the fatigued specimen in the air is more uneven (i.e. more localized strains can be seen) with much more de-bonding failure than samples tested in seawater. A possible reason for the higher number of localized strains is a large number of resin cracks. Indeed microscopic observation of fatigue loaded samples reveals that for those specimens tested in the air many resin cracks are created prior to failure, while only a few resin cracks are found in
Fig. 10 DIC calculated distribution of axial strain through the thickness direction at the length coordinates of $\mathbf{a x}=0$ (centre), b $\mathrm{x}=12.5 \mathrm{~mm}, \mathbf{c} \mathrm{x}=25 \mathrm{~mm}, \mathbf{d}$ $\mathrm{x}=37.5 \mathrm{~mm}, \mathbf{e} \mathrm{x}=50 \mathrm{~mm}($ at support)
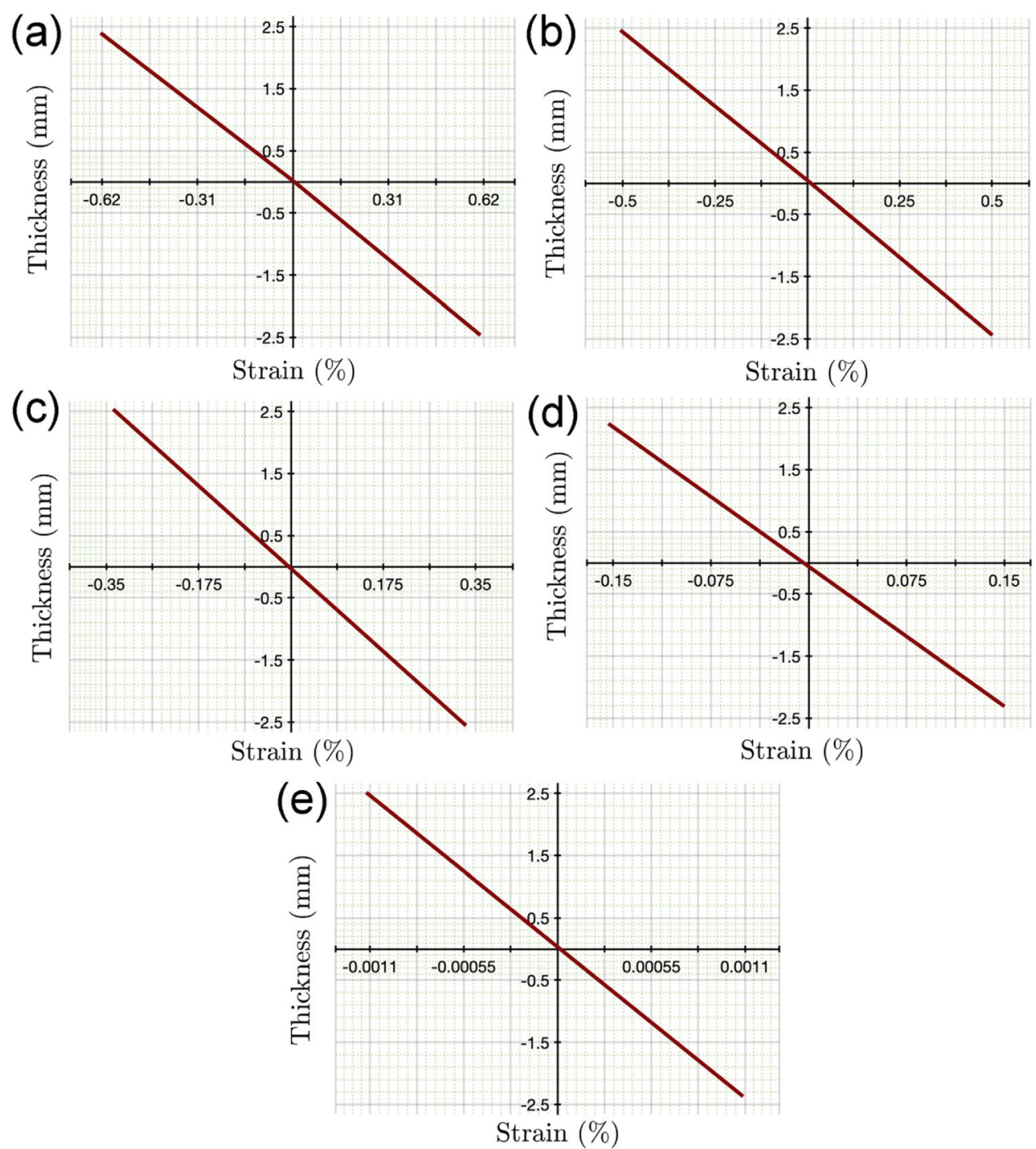
(a)

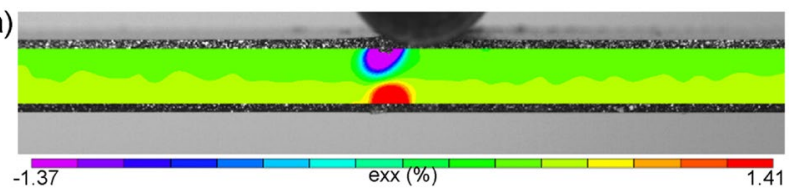

(b)

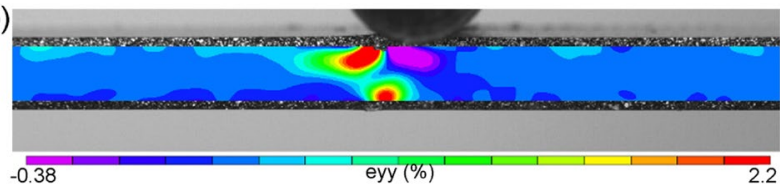

(c)

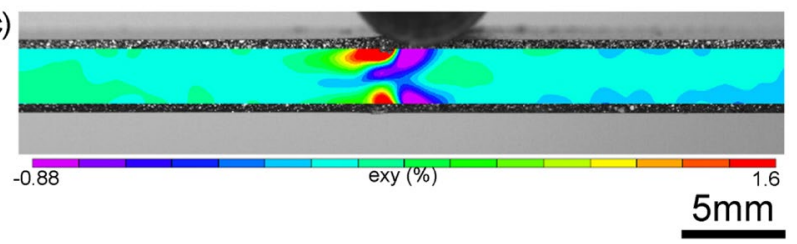

Fig. 11 Lagrange strain tensor components for a $3 \mathrm{~PB}$ fatigue test (seawater environment) at peak cyclic strain equal to $30 \%$ of ultimate static strain and 1.300 million cycles. (a), longitudinal normal strain, $\boldsymbol{e}_{x x}(\mathbf{b})$, transverse normal strain, $\boldsymbol{e}_{y y}$ and (c), shear strain, $\boldsymbol{e}_{x y}$

(a)

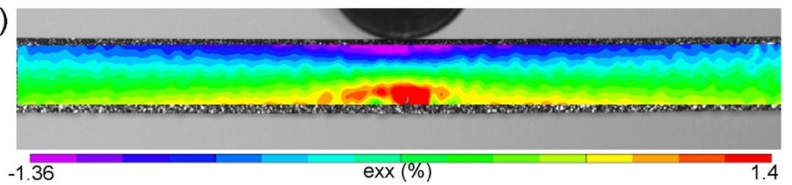

(b)

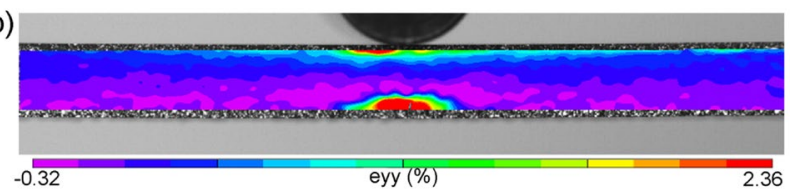

(c)

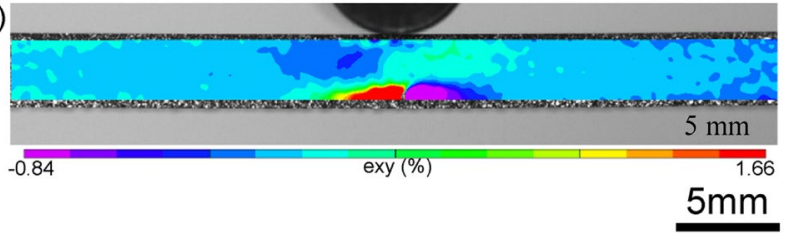

Fig. 12 Lagrange strain tensor components for a 3 PB fatigue test (air environment) at peak cyclic strain equal to $30 \%$ of ultimate static strain and 5.900 million cycles. (a), longitudinal normal strain, $e_{x x}$ (b), transverse normal strain, $e_{y y}$ and (c), shear strain, $e_{x y}$

specimens tested in seawater. This indicates that failure follows quickly after the first crack formation in the seawater environment. Consequently, resin cracking can be accelerated and overall fatigue life is reduced. This description of resin cracking effects in environmental behavior of FRP composites is seen by other authors (Carswell and Roberts 1980, Hofer et al. 1987).

In Figs. 13 and 14, it can be observed that the damage phenomena are concentrated in the central zone near the tension and compression sides of the specimen (starting from the beginning of cycling) and gradually evolve in a concentrated portion of the composite specimen as failure occurs just in the central weaker section. The fatigue loaded specimens in air fail in the tension side while the samples tested in seawater fail in both tension and compression sides suggesting that there may be an environmentally affected fatigue mechanism acting (Price and Hull 1983).

\subsection{Fatigue failure mechanisms}

Fatigue damage evolution is evaluated by the measurement of changes in flexural elastic modulus and investigation of the microstructural features of the sample surface during the fatigue cycling. To reveal information about damage development and understand how fatigue cycling affects the composites, fatigue tests have been interrupted after different proportions of the fatigue life in both high and low cycle fatigue. Then a quasi-static 3 PB test was performed to failure to determine residual flexural modulus as illustrated in Fig. indicating stiffness reduction as a result of cyclic loads. It has been well documented that variation in the flexural elastic modulus is an indication of the failure state for a composite material (Stinchcomb and Reifsnider 1979; Hahn et al. 1980; Konur and Matthews 1989, Agarwal et al. 2017). Such a bending modulus degradation curve is characterized by a drop within the first $10 \%$ of life, followed by a relatively flat region, representing a slower damage development rate, to about $90 \%$ of life and then termination by a sudden drop during the last stages of life. In Sect. 3.5 and 3.6 it has been shown that the modulus decay and fatigue damage accumulation processes in a GFRP woven-fabric composite are divided into three such stages.

During the initial stage of fatigue life, the initiation of fatigue failure is revealed by the appearance of transverse cracks in the fill direction of the weave followed by longitudinal inter-laminar cracks. Transverse matrix cracks usually initiate from the edge of specimen, presumably due to the effects of microdamage during sample cutting. As the cyclic load continues, the crack density increases and this is followed by crack coupling and interfacial de-bonding (Fig. 15). De-bonding between transversely oriented fibers and the matrix may occur as these transverse resin cracks propagate. A rapid decay of modulus during this stage is mainly caused by crack propagation and accumulation in several stress concentration locations.

In the next stage of fatigue life, the main damage mechanism is delamination between adjacent plies and shear failure. Generally, failure modes such as interfacial de-bonding between fibres/matrix and delamination are associated with the difference in interlayer stress which is due to the difference in the load among the layers in the thickness direction of the FRP specimens. Due to the stress concentration associated with the difference in interlayer stress, inter-laminar cracks propagate into the epoxy resin adjacent to the fibers. 
Fig. 13 bending engineering strain history for a 3 PB fatigue test (seawater environment) at peak cyclic strain equal to $30 \%$ of the ultimate static strain and 1.300 million cycles

Fig. 14 bending engineering strain history for a 3 PB fatigue test (air environment) at peak cyclic strain equal to $30 \%$ of the ultimate static strain and 5.900 million cycles

Fig. 15 a Scanning electron micrograph shows interfacial de-bonding between fibres and matrix, b inter-laminar cracks with delamination
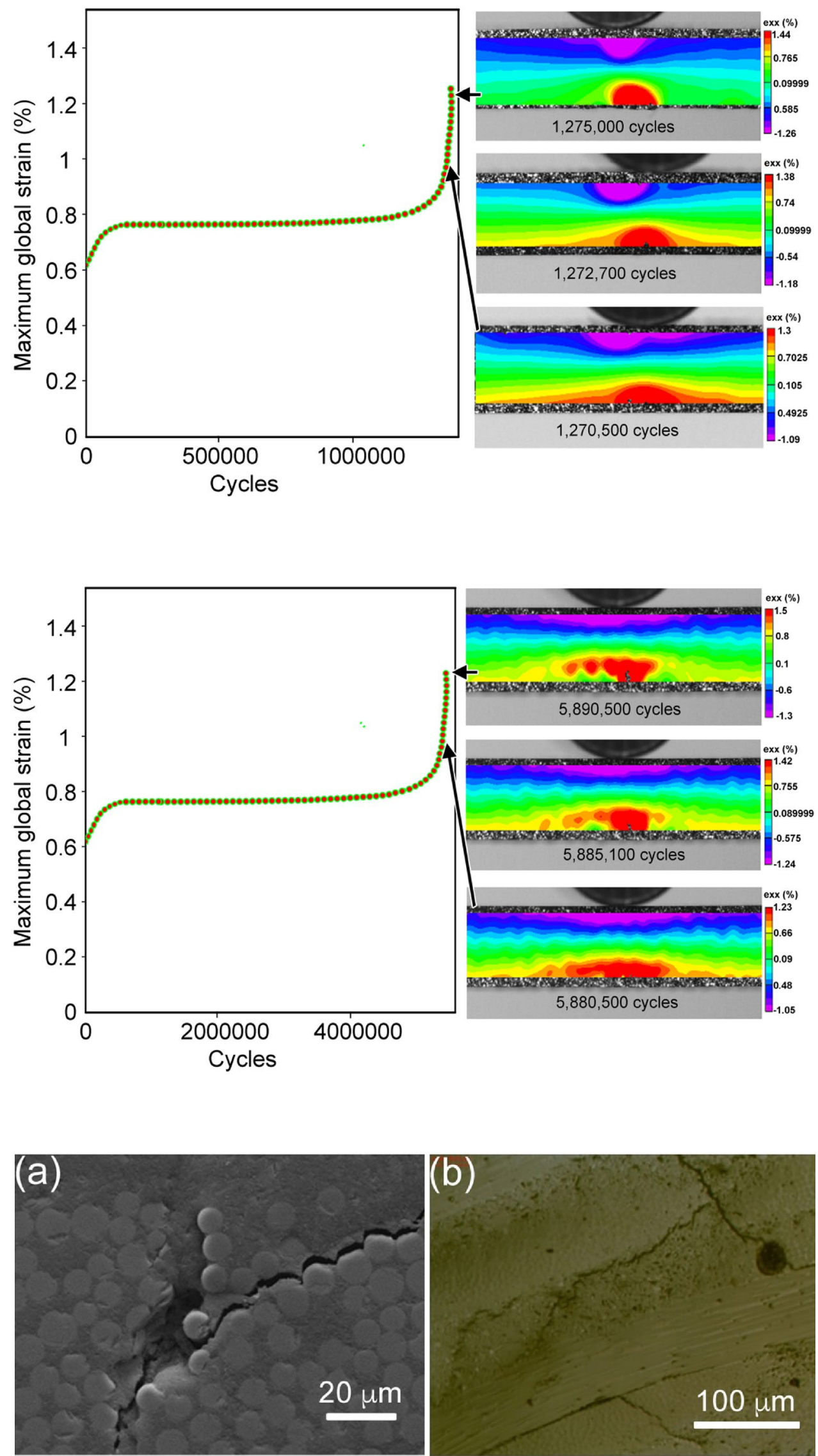
This leads to the creation of fiber-matrix interfacial de-bonding and the crack growth in the fibers.

In the final stage of fatigue life, when the residual strength of the composites is overcome all failure mechanisms are activated and catastrophic failure occurs with the evidence of fiber breakage. Fiber failure happens in two modes; tensile and compressive (Fig. 16).

\subsection{The effect of fiber/matrix interface}

The effect of fiber/matrix interface on the environmentally affected fatigue performance of fiber-reinforced composites has been investigated in a number of studies (Fried 1967, Hofer Jr et al. 1976, Watanabe and Tsai 1979, Hofer et al. 1987, Shih and Ebert 1987). The destruction of the fibre/ matrix interface region by corrosive fluid leakage facilitates matrix crack propagation because fibres no longer sustain their reinforcing roles. This process is further aided by the fact that the failure strain of the matrix (epoxy resin) is diminished upon exposure to seawater. In this study SEM examination of the failed surfaces revealed the nature of the surface of fibers. For specimens tested in dry conditions more matrix material appears attached to the fiber surface. This relatively rough surface of fibers can be seen in Fig. 17a, while "smoother" and cleaner fiber surfaces with less matrix bonded are observed from specimens failed under fatigue in seawater (Fig. 17b). This difference indicates the destructive effect of seawater on the fiber/matrix adhesion. Similar behavior of degraded fiber surface due to the wet conditions has been also reported in (Watanabe and Tsai 1979, Sekine et al. 1988). Consequently, the process of environmentally affected fatigue of GFRP composites, involves combined interaction between the degradation of E-glass/ Epoxy resin interfaces and resin cracking. After crack initiation and propagation in the epoxy resin, access of fluid into the composite occurs at an accelerated rate, which further speeds up the degradation processes in the interphase region. Therefore the glass fibers are exposed to corrosion at a faster rate. From the fatigue data, fiber strength decay cannot be quantified, however, microscopic investigations of the failed specimens can establish a strong indication of fiber strength deterioration.

\subsection{Elastic modulus evolution}

To assess different test results with various strain levels and fatigue life, all measurements of modulus decay are normalized with respect to the maximum values of elastic modulus and the number of cycles to failure. Given the stiffness degradation normalized curves for all fatigue tests (Fig. 18), two slope transition points can be observed; they exist in correspondence with a specified percentage of total fatigue life and three different zones can be identified. The values of these slope transition points for stiffness decay in terms
Fig. 16 Scanning electron micrograph shows fibre breakage as a result of flexural fatigue loads, a tensile failure of fibre in the bottom (tension) side of GFRP specimen, b fibre buckling/kicking in the upper side
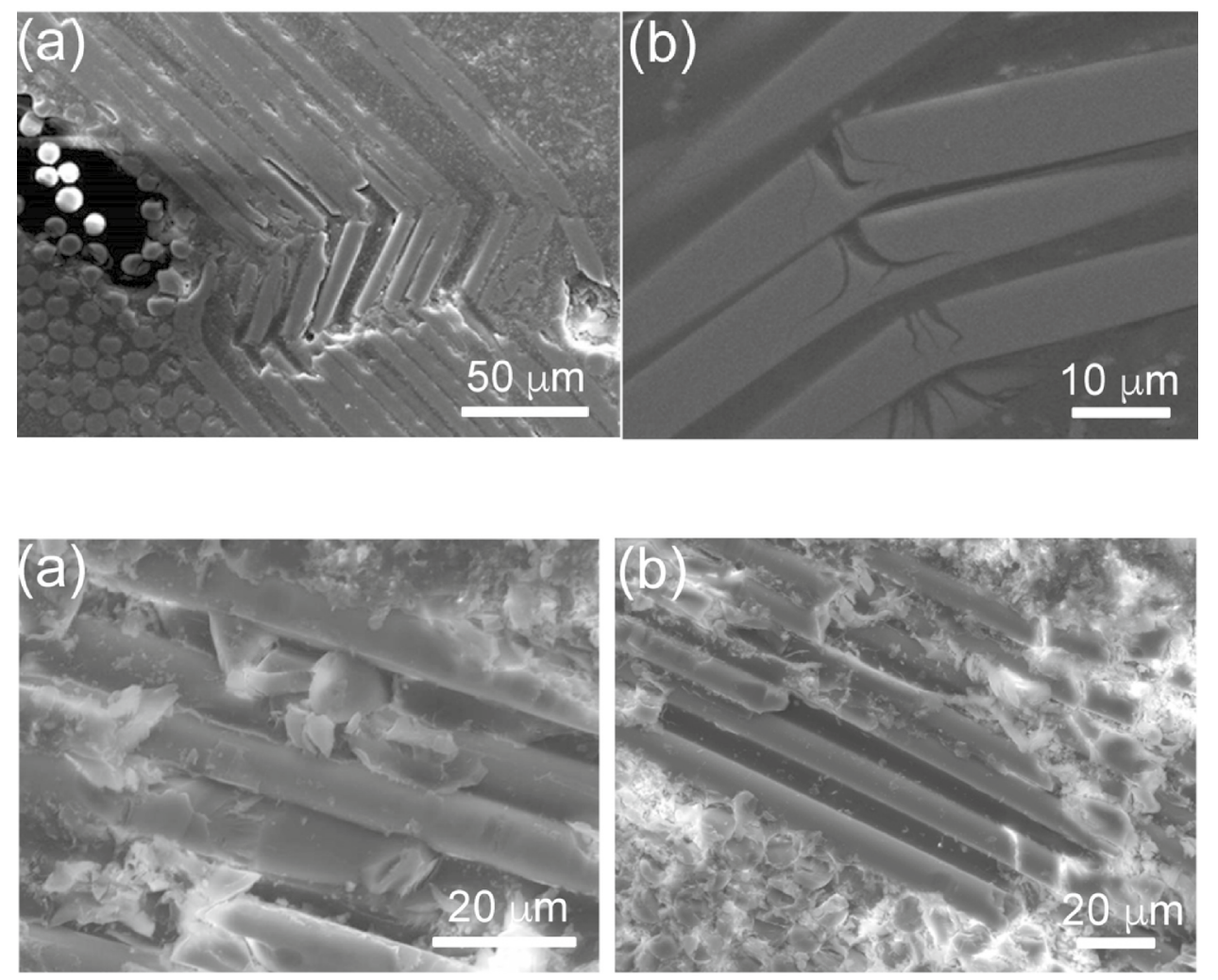

Fig. 17 Scanning electron micrographs of glass fibre surface for specimen failed by cycling in $\mathbf{a}$ air and $\mathbf{b}$ seawater 
Fig. 18 Modulus decay in woven fabric composites during fatigue life in $\mathbf{a}$ dry $\mathbf{b}$ wet condition, the relative standard uncertainty in the normalized modulus data is estimated as $2.5 \%$ (a)

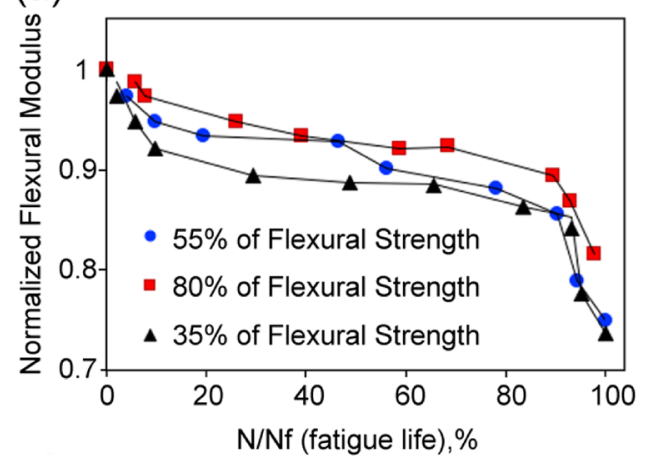

(b)

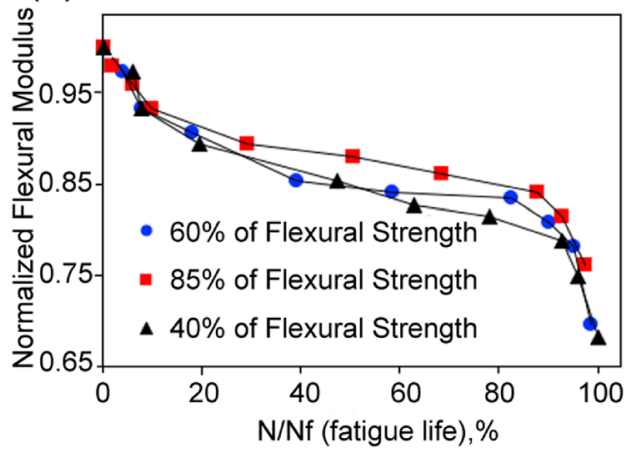

of the number of cycles are positioned at around 10-90\% of total life. Given the modulus decay graphs, the initial phase is dominated by a reduction in stiffness in the order of $5-10 \%$, until an equilibrium stage is reached. This behaviour is influenced by internal fibre-matrix viscoelastic interactions and crack accumulation in several stress concentration locations. The second stage occupies $90 \%$ of consumed fatigue life and is in the same life percentage range for all samples. In addition, the trend in this second phase is quite linear and represents a similar slope regardless of the strain level and environment. The final stage is characterized by coalescence of defects and a huge stiffness reduction can be observed.

\subsection{Fatigue damage estimation}

To determine the damage $(D)$ in GFRP test coupon in terms of residual life to failure, a knowledge of elastic modulus reduction is useful, provided that constant displacement or strain level is applied. Elastic modulus decay has been used to quantify the damage state of composite materials for a long time (Kuo and Pon 1997; Whitworth 1997; Van Paepegem and Degrieck 2002, Tang et al. 2004). In this work, for the calculation of damage $(D)$ an expression is suggested which is a function of Elastic modulus variation;
$D=\frac{E_{\mathrm{i}}-E}{E_{\mathrm{i}}-E_{\mathrm{f}}}$

where $D$ covers a range of values between 0 and 1 and depends on the initial Modulus, $E_{\mathrm{i}}$, and final Modulus, $E_{\mathrm{f}}$. Figure 19 shows the evolution of damage resulting from analysis of modulus decay data using the above expression. These figures and the stiffness degradation curves show that the stiffness degradation and damage state criterion $(D)$ are strictly correlated in fatigue for composite materials and both can express the progressive fatigue damage.

\subsection{Assessment of residual fatigue life}

As shown earlier, the stiffness degradation is well-correlated to the damage state of composite test coupon and both of them can be adopted as a potential damage measure. This means that a method can be suggested to predict the residual fatigue life of GFRP components. A representative example is presented in Fig. 20; drawing a line that fits the second stage of stiffness degradation, it is possible to identify two points: $X_{10}^{\text {lin }}$ : The point of line corresponding to $10 \%$ of consumed fatigue life and $X_{90}^{l i n}$ : The point of line corresponding to $90 \%$ of consumed fatigue life on modulus decay diagram. Thus the following expression can be defined as
Fig. 19 Damage accumulation in woven fabric composites during fatigue life in a dry, $\mathbf{b}$ wet condition, the relative standard uncertainty in the normalized modulus data is estimated as $2.5 \%$ (a)

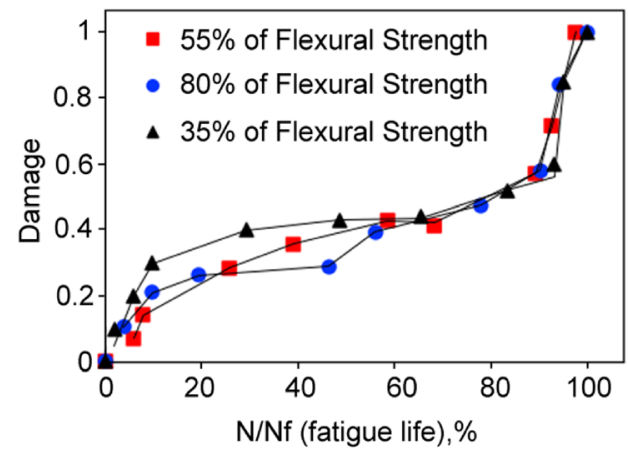

(b)

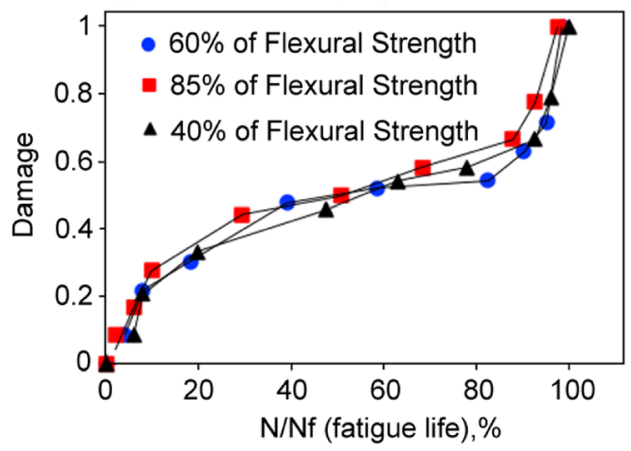




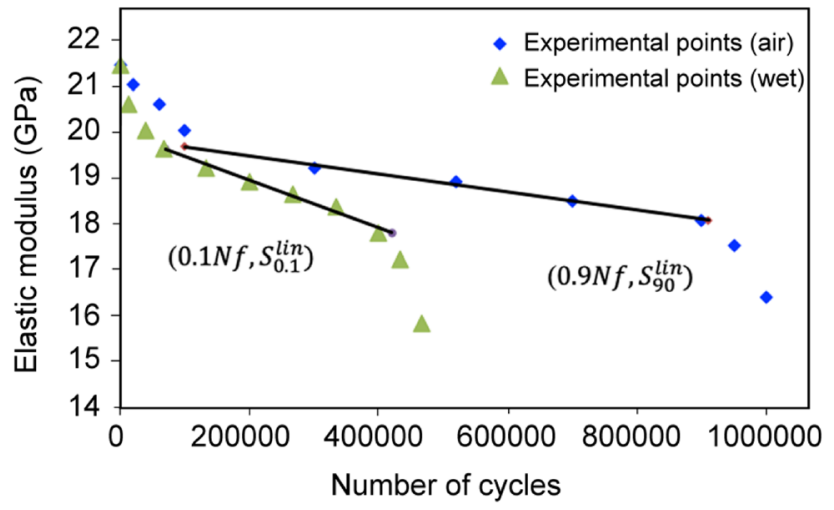

Fig. 20 Elastic modulus evolution and line fitting the second stage (40\% of ultimate Flexural deflection)

$\Delta X_{\%}=\frac{X_{10}^{l i n}-X_{90}^{l i n}}{X_{10}^{l i n}}$

The quantity $(\Delta X)$ is defined as an index of irreversible composite degradation. By measuring this quantity for all strain levels in fatigue tests of GFRP composites, it was found that the modulus decay rate of the fatigue loaded samples in seawater is higher than that in the air.

\subsection{Environmental effects on fatigue crack growth}

With reference to Figs. 13 and 14, it is seen that many cracks in the epoxy resin are created prior to final failure for samples tested in air, however, a only a few cracks were found in specimens tested in seawater. This indicates that the major damage follows immediately after the development of the first cracks in seawater. During the environmental fatigue testing, seawater diffuses into the network of resin cracks and de-bonded fibre/matrix affecting the mechanical properties of the matrix (epoxy resin) and fibre/matrix interface region of the plies and extends rapidly beyond the last cracked ply. In Sect. 3.4, evidence of the destructive effect of seawater on the fibre/matrix interface region was presented. The degraded fibre/matrix interface region is extended by seawater diffusion and can facilitate crack propagation in the matrix since the fibres cannot continue their reinforcing roles in the composite. In addition, once the seawater penetrates the epoxy resin matrix, it can stimulate cracking and crazing in the matrix (Arnold 1996; Wright 1996). As a result, access of seawater into the composite occurs at a higher rate, which further accelerates the degradation in the interface region, finally leading to the significant reduction in fatigue life of the composites when fatigue testing is carried out in seawater. This agrees with the findings in Sect. 3.7, as it is shown that the rate of modulus decay of the samples tested in seawater is higher than the samples tested in the air (Fig. 20).

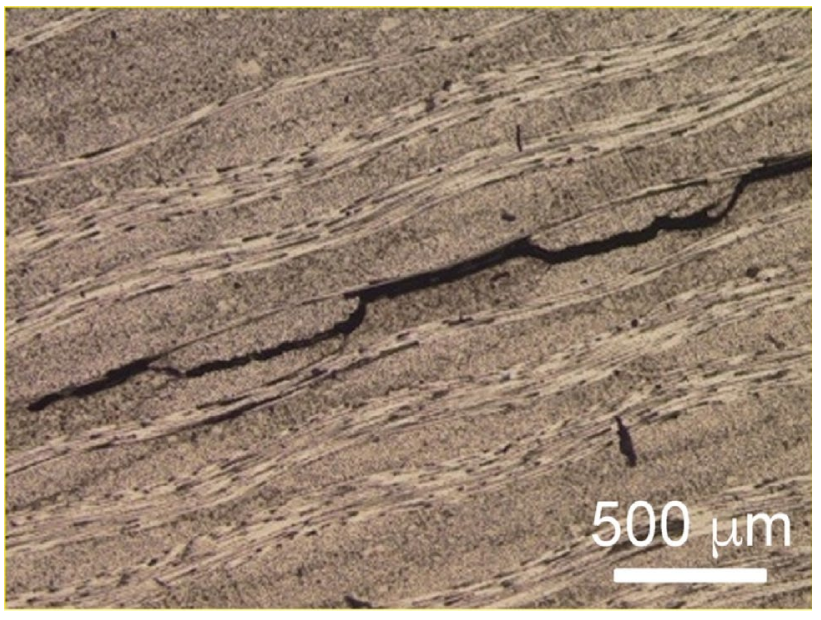

Fig. 21 Micrograph of a typical delamination pattern. The micrograph is taken from the edge of composite test specimens near mid span after fatigue

Therefore, the process of environmentally affected fatigue behavior for the GFRP composite involves resin cracking and fiber/matrix interface degradation. Although the above mechanisms occur in high cycle regimes (low strain levels) of fatigue in Fig. 7 where the difference between fatigue life in the air and seawater is significant, in the low cycle regime (high strain levels), the amount of time required for seawater diffusion is insufficient, therefore no significant difference between fatigue life in seawater and the air is observed. Similar results have been also reported in the literature (Carswell and Roberts 1980, Hofer et al. 1987).

\subsection{Fabric and delamination analysis using $\mu$-CT}

The progression of bending fatigue damage in $0^{\circ} / 90^{\circ}$ oriented glass fiber-reinforced epoxy was previously studied (Sect. 3.3), and delamination within the specimen was observed (Fig. 21). In this figure, characterization of the geometry of delamination required slicing of consecutive sections through the specimen and preparation of each section for optical and/or electron microscopy which is a laborious and destructive process. To determine subsurface damage non-destructively specimens from this study were examined using $\mu-\mathrm{CT}$, and an example is presented here.

The three-dimensional geometry of the delamination is revealed in the volumetric reconstruction in Fig. 22a. The $\mu$ - CT results provide a method to measure the delamination area, without the need for successive sectioning of the sample and the potential for introduction of additional damage during sectioning. Figure $22 \mathrm{~b}$ and $\mathrm{c}$ presents a slice $(19.6 \mu \mathrm{m}$ voxels) revealing the delamination. The location of this cross-section is identified by the cutting plane line in the central region of a fatigued specimen where macroscopic 
Fig. 22 E-glass/epoxy fatigue loaded specimen with delamination, a volumetric reconstruction of the delamination in the micro-CT specimen, b Micro$\mathrm{CT}$ reconstructed cross-section of the specimen in $\mathrm{x}-\mathrm{z}$ plane, $\mathbf{c}$ Micro-CT reconstructed crosssection of the specimen in $\mathrm{x}-\mathrm{y}$ plane

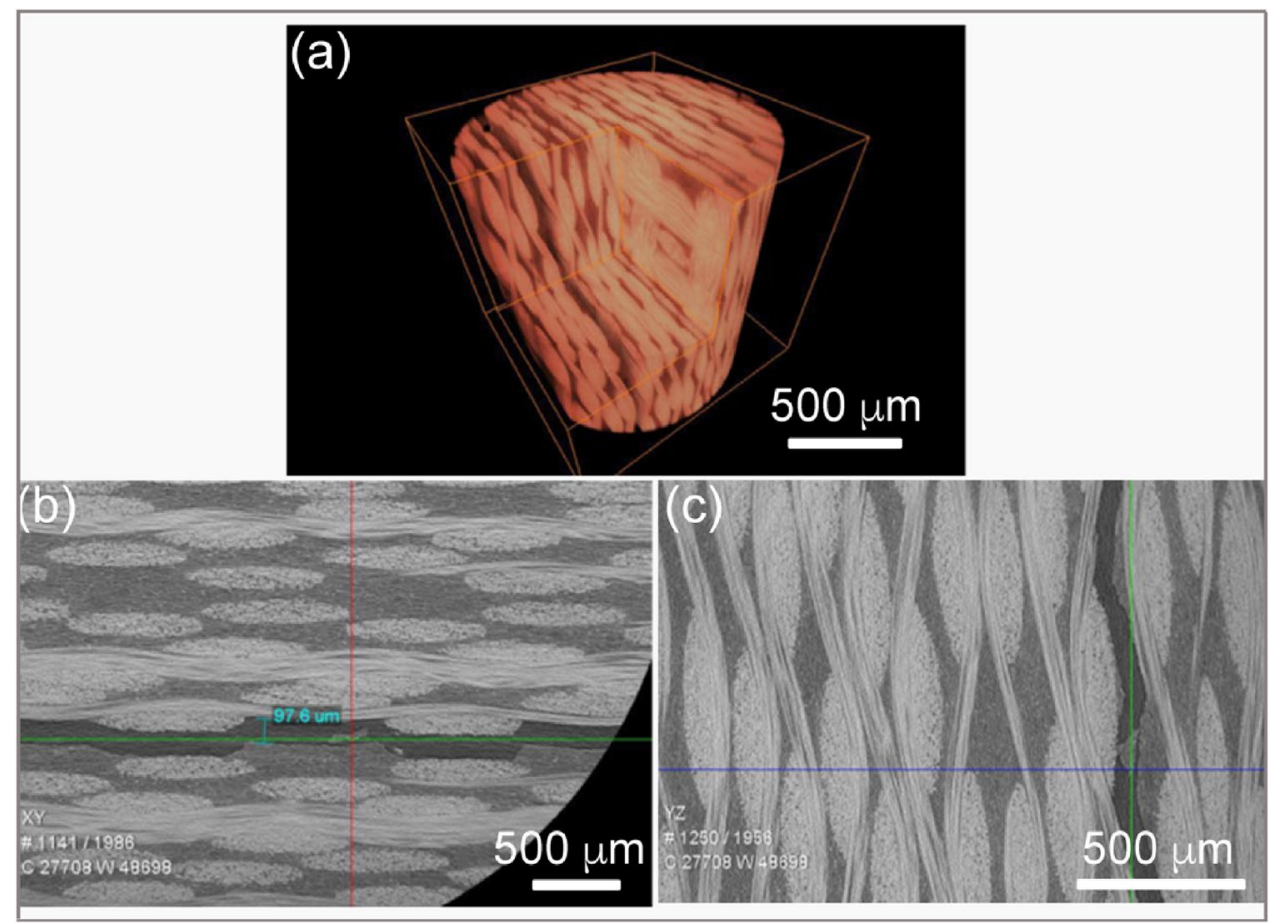

failure was observed. The delamination is resolved based on the difference in X-ray absorption between the glass/ epoxy material and air. The delaminated area had a lower absorption coefficient than the composite plies and appears darker in the image. This clearly matches the delamination geometry observed at the surface by optical and electron microscopy (comparing Figs. 21 and 22b). Therefore, the $\mu-C T$ can provide an excellent characterization of the $3 \mathrm{D}$ damage geometry.

\subsection{State of the art}

Tidal turbine blades are fatigue critical components and degradation of blade material (fibre reinforced composites) under combined effects of cyclic loads and seawater environment are the major considerations in the design of the blades (Davies et al. 2013, Jaksic et al. 2018, Izadi Gonabadi 2019). Although in recent years, novel techniques for manufacturing fibre-reinforced composites tidal turbine blades with improved properties have been investigated (Robert et al. 2019; Murray et al. 2020), accounting for the environmental degradation of the composite is an essential element for multi-scale Finite Element modelling of composite blades and it requires reliable fatigue testing data input. The approach to account for the environmental degradation of composite materials, based on testing samples in the seawater condition is developed in this study involving interaction between seawater diffusion and mechanical loading, thus providing a more realistic estimation of the environmentally affected fatigue behaviour of the composite and the degradation mechanisms of composite for tidal turbine applications.

Although in the literature (Kennedy et al. 2012, Li et al. 2014, Suzuki 2017, Jaksic et al. 2018) models for fatigue life prediction of FRP composite tidal turbine blades have been proposed, the fatigue testing technique to provide the input test data ( $\mathrm{S}-\mathrm{N}$ curves) for the majority of these models ignore either the effects of environmental conditions or the bending mode on the composites leading to an overestimation of life.

In the present study, in order replicate the bending behavior of the blade, associated stresses and failure modes, bending fatigue testing is employed to characterize the strain-life behavior of composites specimens under more realistic marine conditions. The results show that high cycle fatigue of GFRP composites is a stress and environment-dependent regime, meaning that the combined effect of stress and environment is significant and therefore a higher safety factor should be considered by tidal turbine designers. In addition, the better understanding of microscopic failure mechanisms of composite constituents under combined effect of seawater condition and cyclic loading obtained in the present study should help the designer to consider the magnitude of the extra safety factors necessary when selecting these materials for tidal turbine applications. 


\section{Conclusions}

For the specimens cyclically loaded in the low cycle regime above $60 \%$ of the maximum flexural strain, no substantial difference in fatigue life was recorded in air or seawater. However, for the specimens cyclically loaded in the high cycle regime below $60 \%$ of the dry maximum flexural strain, all specimens tested in air survived beyond $10^{6}$ cycles, while all those tested in the seawater environment did not. Consequently, it is found that the long-term environmental fatigue performance of woven GFRP composites is controlled by a combination of both load and the fluid environment.

Microscopic observation of fatigue failed samples reveals that for those specimens tested in the air many resin cracks are created prior to failure, while only a few resin cracks are found in specimens fatigued in the seawater. The higher number of resin cracks can be seen by distributed localized strain in DIC maps and this technique clearly confirms the existence of more resin cracks in the fatigue failed samples in the air than in seawater. In addition, the greater accumulated damage in samples tested in seawater shows that failure follows quickly after the first crack formation. This is due to the fact that seawater enters into resin cracks and is quickly distributed through the sample. This is the reason why the DIC strain map for seawater affected fatigue samples shows damage concentration only in limited zones near the top and bottom sides, however, in the case of the air environment, the DIC strain map is more uneven due to the larger number of resin cracks.

From the investigation of stiffness degradation curves (modulus decay) during the fatigue testing, it was found that $80 \%$ of fatigue life is taken in the second stage where delamination is the main failure mode, therefore controlling the rate of delamination plays an important role in increasing the fatigue life of composite structures.

Microscopic examination of the fatigued test coupons reveals a degraded fibre/matrix interface region in those samples where environmental exposure caused the premature failure. It is believed that fibre/matrix interfacial degradation is the controlling factor in the environmentally affected fatigue behavior of GFRP composites.

The $\mu$ - CT results provide a method to measure the delamination area, without the need for successive sectioning of the sample and the introduction of additional damage during sectioning.

Acknowledgements We thank our colleagues from the REC-ASM and NECEM projects who provided insight and expertise that greatly assisted the research.

Funding This research was supported by EPSRC through the ReCASM (EP/K013319/1) and NECEM (EP/R021503/1) projects.

Data availability The data associated with this paper is available and can be provided.

\section{Compliance with ethical standards}

Conflicts of interest There are no conflicts of interest associated with the submission of this manuscript.

Ethics approval No formal ethical approval was required to carry out this research. The work described has not been published before.

Consent to participate Each author has participated in the work. HIG carried out the mechanical and fatigue test experiments with the assistance of AY who also took an important role in the microscopy. AO and SJB planned and directed the research and approved the publication.

Consent for publication All authors give consent for publication.

Open Access This article is licensed under a Creative Commons Attribution 4.0 International License, which permits use, sharing, adaptation, distribution and reproduction in any medium or format, as long as you give appropriate credit to the original author(s) and the source, provide a link to the Creative Commons licence, and indicate if changes were made. The images or other third party material in this article are included in the article's Creative Commons licence, unless indicated otherwise in a credit line to the material. If material is not included in the article's Creative Commons licence and your intended use is not permitted by statutory regulation or exceeds the permitted use, you will need to obtain permission directly from the copyright holder. To view a copy of this licence, visit http://creativecommons.org/licenses/by/4.0/.

\section{References}

Abanto-Bueno J, Lambros J (2002) Investigation of crack growth in functionally graded materials using digital image correlation. Eng Fract Mech 69(14-16):1695-1711

Agarwal BD, Broutman LJ, Chandrashekhara K (2017) Analysis and performance of fiber composites. Wiley

Ahamed RAR et al (2016) Impact angle effects on erosion maps of GFRP: applications to tidal turbines. J Bio- Tribo-Corr 2(2):14

Arnold J (1996) Environmental stress crack initiation in glassy polymers. Trends Poly Sci 12(4):403-408

Boisseau A et al (2013) Fatigue behaviour of glass fibre reinforced composites for ocean energy conversion systems. Appl Compos Mater 20(2): 145-155

STANDARD B, ISO B (1998) Fibre-reinforced plastic compositesDetermination of flexural properties

Canal LP et al (2012) Application of digital image correlation at the microscale in fiber-reinforced composites. Compos A Appl Sci Manuf 43(10):1630-1638

Carswell WS, Roberts RC (1980) Environmental fatigue stress failure mechanism for glass fibre mat reinforced polyester. Composites 11(2):95-99

Charles R (1958a) Static fatigue of glass. I. J Appl Phys 29(11):1549-1553

Charles R (1958b) Static fatigue of glass. II. J Appl Phys 29(11):1554-1560

Chu TC et al (1985) Applications of digital-image-correlation techniques to experimental mechanics. Exp Mech 25(3):232-244

Crupi V, Guglielmino E, Risitano G, Tavilla F (2013) Application of Digital Image Correlation for the effect of glass fibres on the strength and strain to failure of polyamide plastics. Gruppo Italiano Frattura. Convegno Nazionale IGF. Acta Fracturae, 22, 287 
Davies P et al (2013) Evaluation of the durability of composite tidal turbine blades. Philosoph Transactions Royal Soc A Math Phys Eng Sci 371(1985):20120187

Fried N (1967) Degradation of composite materials: the effect of water on glass-reinforced plastics. Pergamon Press, Pensylvania, Mechanics of Composite Materials

Giancane $S$ et al (2010) Characterization of fatigue damage in long fiber epoxy composite laminates. Int J Fatigue 32(1):46-53

Godara A, Raabe D (2007) Influence of fiber orientation on global mechanical behavior and mesoscale strain localization in a short glass-fiber-reinforced epoxy polymer composite during tensile deformation investigated using digital image correlation. Compos Sci Technol 67(11):2417-2427

Hahn HT, HT H., TT C (1980) Long-term behavior of composite materials, vol 1; pp 584-596; BIBL. 17 REF.; ISBN 0-08-026717-3

$\mathrm{He} \mathrm{Y}$ et al (2012) Characterization of nonlinear shear properties for composite materials using digital image correlation and finite element analysis. Compos Sci Technol 73:64-71

Hofer Jr KE, et al. (1976). Effect of various fiber surface treatments on the fatigue behavior of glass fabric composites in high humidity environment. Proceeding of the 31st Annual Technical Conference of SPI, Washington (DC)

Hofer KE et al (1987) Effect of moisture on fatigue and residual strength losses for various composites. J Reinf Plast Compos 6(1):53-65

ISO B (2003) 13003. Fibre-reinforced plastics-determination of fatigue properties under cyclic loading conditions. British Standards International

Izadi Gonabadi H (2019) Performance of low cost composites for tidal turbine applications. PhD diss., Newcastle University

Jaksic V et al (2018) Influence of composite fatigue properties on marine tidal turbine blade design. Durab Comp Mar Env 2:195223 (Springer)

Johnson KL, Johnson KL (1987) Contact mechanics. Cambridge university press

Kennedy CR et al (2012) A preliminary design methodology for fatigue life prediction of polymer composites for tidal turbine blades. Proceed Instit Mech Eng Part L J Mater Des Appl 226(3):203-218

Konur O, Matthews FL (1989) Effect of the properties of the constituents on the fatigue performance of composites: a review. Composites 20(4):317-328

Kuo W-S, Pon B-J (1997) Elastic moduli and damage evolution of three-axis woven fabric composites. J Mater Sci 32(20):5445-5455

Laurin F et al (2012) Determination of the properties of composite materials thanks to digital image correlation measurements. Procedia IUTAM 4:106-115

Lee D et al (2009) Experimental study of dynamic crack growth in unidirectional graphite/epoxy composites using digital image correlation method and high-speed photography. J Compos Mater 43(19):2081-2108

Li $\mathrm{H}$ et al (2014) Reliability-based fatigue life investigation for a medium-scale composite hydrokinetic turbine blade. Ocean Eng $89: 230-242$

Mamalis D et al (2019) Novel carbon-fibre powder-epoxy composites: interface phenomena and interlaminar fracture behaviour. Compos B Eng 174:107012

McCormick N, Lord J (2010) Digital image correlation. Mater Today 13(12):52-54

Metcalfe A, Schmitz G (1972) Mechanism of stress-corrosion in e glass filaments. Glass Technol 13(1):5-000

Metwalli S et al (1987) Determination of plastic stress-strain behavior by digital-image-processing techniques. Exp Mech 27(4):414-422

Murray JJ et al (2020) Manufacturing of unidirectional stitched glass fabric reinforced polyamide 6 by thermoplastic resin transfer moulding. Mater Des 189:108512
Price JN, Hull D (1983) Propagation of stress corrosion cracks in aligned glass fibre composite materials. J Mater Sci 18(9):2798-2810

Quaresimin M et al (2010) Fatigue behaviour and life assessment of composite laminates under multiaxial loadings. Int J Fatigue 32(1):2-16

Rasool G et al. (2016) Tribology of tidal turbine blades: impact angle effects on erosion of polymeric coatings in sea water conditions, Asian Wave and Tidal Energy Conference (AWTEC)

Rasool G, Stack MM (2019) Some views on the mapping of erosion of coated composites in tidal turbine simulated conditions. Tribol Trans 62(3):512-523

Rasool G et al (2016) Mapping synergy of erosion mechanisms of tidal turbine composite materials in sea water conditions. J Bio Tribo-Corr 2(2):13

Renaud CM, Greenwood ME (2005) Effect of glass fibres and environments on long-term durability of GFRP composites. In: Proceedings of 9 EFUC Meeting, Wroclaw, Poland

Richter-Trummer V et al (2011) Analysis of crack growth behavior in a double cantilever beam adhesive fracture test by different digital image processing techniques. Materialwiss Werkstofftech 42(5):452-459

Robert C, Pecur T, McCarthy ED, Brádaigh C (2019) Tidal turbine blade composites using basalt fibre reinforced powder epoxy. Engineers Australia, Barton, Australia, p 3687. https://www.resea rchgate.net/publication/339725966

Schaff JR, Davidson BD (1997) Life prediction methodology for composite structures. Part I-Constant amplitude and two-stress level fatigue. J Compos Mater 31(2):128-157

Schmitz G, Metcalfe A (1966) Stress corrosion of E-glass fibers. Indust Eng Chem Product Res Develop 5(1):1-8

Sekine $\mathrm{H}$ et al (1988) Strength deterioration and degradation mechanism of glass chopped reinforced plastics in water environment. JSME Int J Ser Solid Mech Strength Mater 31(3):619-626

Shih GC, Ebert LJ (1987) The effect of the fiber/matrix interface on the flexural fatigue performance of unidirectional fiberglass composites. Compos Sci Technol 28(2):137-161

Shokrieh MM, Lessard LB (1997) Multiaxial fatigue behaviour of unidirectional plies based on uniaxial fatigue experiments-II. Experimental evaluation. Int J Fatigue 19(3):209-217

Stinchcomb WW, Reifsnider KL (1979) Fatigue damage mechanisms in composite materials: a review. Fatigue mechanisms. https://www. astm.org/DIGITAL_LIBRARY/STP/PAGES/STP35914S.htm

Sun $\mathrm{Z}$ et al (1997) Measuring microscopic deformations with digital image correlation. Opt Lasers Eng 27(4):409-428

Suri C, Perreux D (1995) The effects of mechanical damage in a glass fibre/epoxy composite on the absorption rate. Compos Eng $5(4): 415-424$

Suzuki T (2017) Development of a comprehensive design methodology and fatigue life prediction of composite turbine blades under random ocean current loading (Doctoral dissertation, Florida Atlantic University). https://search.proquest.com/docview/2015527971 ?pq-origsite $=$ gscholar $\&$ fromopenview $=$ true

Tang R et al (2004) An appropriate stiffness degradation parameter to monitor fatigue damage evolution in composites. Int J Fatigue 26(4):421-427

Ukyo S, Masuda M (2004) Investigation of the true stress-strain relation in shear using the digital image correlation method. J Jpn Wood Res Soc (Japan). https://agris.fao.org/agris-search/searc h.do?recordID $=$ JP2004007630

Van Paepegem W, Degrieck J (2002) A new coupled approach of residual stiffness and strength for fatigue of fibre-reinforced composites. Int J Fatigue 24(7):747-762

Vassilopoulos AP, Keller T (2011) Fatigue of fiber-reinforced composites. Springer Science \& Business Media. https://doi. org/10.1007/978-1-84996-181-3 
Vauthier E, et al. (1995). Hygrothermal aging and durability of unidirectional glass-epoxy composites. Tenth international conference on composite materials. VI. Microstructure, Degradation, and Design

Watanabe M and TW Tsai (1979) Effect of water environment on fatigue behavior of fiberglass reinforced plastics. Composite materials: testing and design (Fifth conference), ASTM STP

Whitworth HA (1997) A stiffness degradation model for composite laminates under fatigue loading. Compos Struct 40(2):95-101

Wright DC (1996) Environmental stress cracking of plastics. iSmithers Rapra Publishing
Zhang D et al (2006) Displacement/strain measurements using an optical microscope and digital image correlation. Optical Eng 45:3 (033605-033605-033609)

Publisher's Note Springer Nature remains neutral with regard to jurisdictional claims in published maps and institutional affiliations. 